\title{
Mono- and bicyclic alkanes and diamondoid hydrocarbons in the Cretaceous/Tertiary boundary sediments at Kawaruppu, Hokkaido, Japan
}

\author{
AKIRA SHIMOYAMA* and HIKARU YABUTA \\ Department of Chemistry, University of Tsukuba, Tsukuba 305-8571, Japan
}

(Received October 29, 2001; Accepted January 7, 2002)

\begin{abstract}
Sixty-two mono- and 4 bicyclic alkanes, and 11 diamondoid hydrocarbons were detected in the Cretaceous-Tertiary (K/T) boundary sediments at Kawaruppu, Hokkaido, Japan. The monocyclic alkanes included series of $n$-alkylcyclohexanes, methyl- $n$-alkylcyclohexanes and $n$-alkylcyclopentanes, and other alkylcyclohexanes. The bicyclic alkanes included bicyclo[3.3.1]nonane, trans-decalin, and methyldecalins. The diamondoid hydrocarbons included adamantane, and methyl- and dimethyladamantanes, and diamantane and methyldiamantanes. These mono- and bicyclic alkanes were detected at a level of $0.001-0.1 \mathrm{nmol} \mathrm{g}^{-1}$ and the diamondoid hydrocarbons were at the same or one order magnitude less than those of the cyclic alkanes. Concentrations of all cyclic alkanes within the K/T boundary claystone were markedly small compared to those in the sediments above and below the claystone. The molecular distributions of $n$ alkylcyclohexanes, methyl- $n$-alkylcyclohexanes and $n$-alkylcyclopentanes were relatively smooth within the claystone. On the other hand, those of $n$-alkylcyclohexanes and methyl- $n$-alkylcyclohexanes showed predominances from $\mathrm{C}_{15}$ to $\mathrm{C}_{18}$ and those of $n$-alkylcyclopentanes showed even carbon number predominances from $\mathrm{C}_{16}$ to $\mathrm{C}_{22}$ in the sediments above and below the boundary claystone. These characteristic features in concentration and molecular distribution within the boundary claystone are likely related to the large biomass extinction event at the end of the Cretaceous. Compositions of compounds among trimethylcyclohexanes, methylethylcyclohexanes, decalins, methyladamantanes, and methyldiamantanes were roughly constant over sedimentary sequence. This indicated that diagenetic effect to these compounds had been nearly constant over the sedimentary sequence.
\end{abstract}

\section{INTRODUCTION}

Cyclic alkanes are commonly present in sediments and crude oils. Many studies on these compounds in geochemical materials have dealt with tri-, tetra-, and pentacyclic alkanes such as steranes and hopanes mainly because of the interest in molecular biomarkers in relation to their sources and maturity parameters on organic diagenesis (Farrimond et al., 1998; Alberdi et al., 2001; Inaba et al., 2001). On the other hand, studies of mono- and bicyclic alkanes have been reported rather infrequently. Of these compounds, $n$-alkylcyclohexanes ( $n$-alkylCHs, $\mathrm{C}_{10}-\mathrm{C}_{26}$ ), me- thyl- $n$-alkylcyclohexanes (Me- $n$-alkylCHs, $\mathrm{C}_{14}$ $\mathrm{C}_{26}$ ) (Rubinstein and Strausz, 1979; Ingram et al., 1983; Fowler and Douglas, 1984; Fowler et al., 1986; Hoffmann et al., 1987; Yamamoto et al., $1990)$, and $n$-alkylcyclopentanes ( $n$-alkylCPs, $\mathrm{C}_{10}-\mathrm{C}_{26}$ ) (Ingram et al., 1983; Yamamoto et al., 1990) in sediments and crude oils have been detected. Cyclic alkanes from $\mathrm{C}_{9}$ to $\mathrm{C}_{11}$ are present in these geological samples, but their concentrations are in minute probably due to their relatively high volatility (Peters and Moldowan, 1993; Berthod et al., 1998). Diamondoid hydrocarbons have been detected in crude oils and source rocks, and their molecular distributions have been dis-

*Corresponding author (e-mail: ashimoya@staff.chem.tsukuba.ac.jp) 
cussed (Wingert, 1992; Chen et al., 1996; Dahl et al., 1999; Grice et al., 2000; Jinggui et al., 2000; Schulz et al., 2001).

Massive extinctions of organisms ranging from dinosaurs to marine plankton occurred at the end of the Cretaceous (approximately 65 million years ago). Subsequently, the extinction event must have left notable signatures of biological organic compounds in the Cretaceous-Tertiary (K/T) boundary sediments. The $\mathrm{K} / \mathrm{T}$ boundary sediments at Kawaruppu, Hokkaido, Japan are suitable for studies of the extinction event, because the boundary claystone is thicker $(c a .14 \mathrm{~cm})$ than those at other sites (e.g., Stevns Klint in Denmark, Gubbio in Italy, Woodside Creek in New Zealand, and Caravaca in Spain). Studies of the K/T boundary sediments at Kawaruppu dealt with planktonic foraminifera (Kaiho and Saito, 1986; Kaiho, 1992), palynomorphs (Saito et al., 1986), sulfur isotopes (Kajiwara and Kaiho, 1992), and Ir accumulation and clay minerals (Tazaki et al., 1992).

The K/T boundary sediments at Kawaruppu are also appropriate for analyses of organic compounds. The $14 \mathrm{~cm}$ thickness corresponds to a time span of $c a .9000$ years based on the studies by Saito et al. (1986) and Kajiwara and Kaiho (1992). This time span might have been enough for some organisms to recover to the abundance level in the Cretaceous as revealed, for example, by $n$-alkanes, pristane and phytane (Mita and Shimoyama, 1999a) or not enough for others as shown by the $\mathrm{C}_{25}$ highly branched isoprenoid thiophene (Katsumata and Shimoyama, 2000). Other studies of organic compounds in the Kawaruppu sediments are of amino acids (Mita et al., 1996) and dicarboxylic acids (Mita et al., 1998) for the search of extraterrestrial compounds, polycyclic aromatic hydrocarbons of combustion origin by wild fires (Mita and Shimoyama, 1999b), and maleimides possibly derived from chlorophyll (Shimoyama et al., 2001).

In this study, we analyzed for mono- and bicyclic alkanes, and diamondoid hydrocarbons (adamantanes and diamantanes) in the $\mathrm{K} / \mathrm{T}$ boundary sediments at Kawaruppu, using the analytical technique which was employed in our study of the
Neogene sediments (Yabuta et al., 2002). Here we report the results of the analyses and describe characteristic distributions of these cyclic alkanes above, within and below the boundary claystone in relation to the extinction event.

\section{EXPERIMENTAL}

\section{Samples}

The K/T boundary sediments occurring near Kawaruppu Town, Tokachi District, Hokkaido, their location and lithology were reported by Saito et al. (1986), and Kaiho and Saito (1986). The sedimentary sequence at Kawaruppu consists predominantly of a marine, dark gray siltstone, bearing occasional calcareous concretions. The boundary claystone is grayish black and nearly $14 \mathrm{~cm}$ thick. These sediment samples were kindly provided by Prof. Y. Kajiwara of the University of Tsukuba. The sediment sample horizons were shown in previous reports (Mita et al., 1996, 1998). In this study, 11 sediment samples within the boundary claystone $(0-13.7 \mathrm{~cm}), 5$ samples above (40-495 cm) and 6 samples below $(-395-0$ $\mathrm{cm})$ the boundary clay stone were used, in which the bottom of the boundary claystone was set to 0 $\mathrm{cm}$ in relative depth.

\section{Analyses}

For each analysis, $2 \mathrm{~g}$ of a pulverized sediment sample were extracted with $5 \mathrm{ml}$ hexane for 30 min by sonication and the supernatant after centrifugation was recovered. This extraction and centrifugation process was repeated 6 times. The supernatants were combined, concentrated under reduced pressure, and applied to a silica gel column $(220 \mathrm{~mm} \times 10 \mathrm{~mm}$ i.d.; Keiselgel-60, Merk $)$. From the column cyclic alkanes were eluated with $15 \mathrm{ml}$ hexane. The hexane eluate was concentrated to $50 \mu 1$ under a nitrogen flow for the analysis by a gas chromatograph (GC) combined with a mass spectrometer (MS) (Hewlett Packard G1800 GCD System). The GC was equipped with a DB-5 (30 $\mathrm{m} \times 0.25 \mathrm{~mm}$ i.d., $0.1 \mu \mathrm{m}$ thick $)$ or a TC-1 (60 $\mathrm{m} \times 0.25 \mathrm{~mm}$ i.d., $0.25 \mu \mathrm{m}$ thick) capillary column. The oven temperature was programmed to 
hold at $40^{\circ} \mathrm{C}$ for $10 \mathrm{~min}$, and to increase from 40 to $70^{\circ} \mathrm{C}$ at a rate of $1^{\circ} \mathrm{C} \mathrm{min}^{-1}$ and from 70 to $300^{\circ} \mathrm{C}$ at a rate of $3^{\circ} \mathrm{C} \min ^{-1}$. The mass spectra were acquired every $0.5 \mathrm{~s}$ over $\mathrm{m} / \mathrm{z} 45$ to 425 in an electron impact ionization mode at $70 \mathrm{eV}$. Identification and quantification of compounds were made by comparison of peak retention times on the mass fragmentograms of their major or molecular ions and mass spectra, and peak areas, respectively, with those of standard compounds. For compounds without standards, identification was made by comparisons of mass spectra with library data of the National Institute of Standards and Technology (NIST), USA (1992) or data reported in literature. Individual references of these data will be cited in appropriate places in RESULTS and DISCUSSION. Relative concentrations of isomers and homologues were obtained by comparison of peak areas on the mass fragmentograms of their major or molecular ions.

Hexane (Analytical Grade, Wako Pure Chem.) was distilled twice and used. All glassware was heated at $500^{\circ} \mathrm{C}$ for at least $3 \mathrm{~h}$ before use to eliminate organic contaminants. A procedural blank was carried out with $1 \mathrm{~g}$ pre-ignited sea sand powder and it was found that there was no significant contamination during the analysis.

\section{RESULTS}

\section{Monocyclic alkanes}

Figure 1 shows mass fragmentograms of $\mathrm{m} / \mathrm{z}$ 83, 97, and 69 for compounds recovered from the sediment $(0.8-1.8 \mathrm{~cm})$ within the boundary claystone. $n$-AlkylCHs from $\mathrm{C}_{9}$ to $\mathrm{C}_{26}(\mathrm{~m} / \mathrm{z}, 83)$, Me- $n$-alkylCHs from $\mathrm{C}_{9}$ to $\mathrm{C}_{24}(\mathrm{~m} / z$ 97), $n$ alkylCPs from $\mathrm{C}_{9}$ to $\mathrm{C}_{26}(\mathrm{~m} / \mathrm{z}, 69)$, and other alkylCHs of $\mathrm{C}_{9}$ and $\mathrm{C}_{10}(\mathrm{~m} / \mathrm{z} 69,83$, and 97) were detected. Particularly, peaks of $n$-alkylCHs and $n$ alkylCPs with the same carbon numbers were noted as individual compounds by expanding parts of the two mass fragmentograms and the total ion chromatogram, although retention times of some of the two series were very close to each other in Fig. 1. Their mass spectra were also distinguishable from each other by the intensity ratio of the $m / z 83$ to 69 . A series of $n$-alkylCHs and 11 alkylCHs $\left(\mathrm{C}_{9}\right.$ and $\left.\mathrm{C}_{10}\right)$ were identified by standard compounds and data by NIST. A series of $n$ alkylCPs was identified by data by Yamamoto $e t$

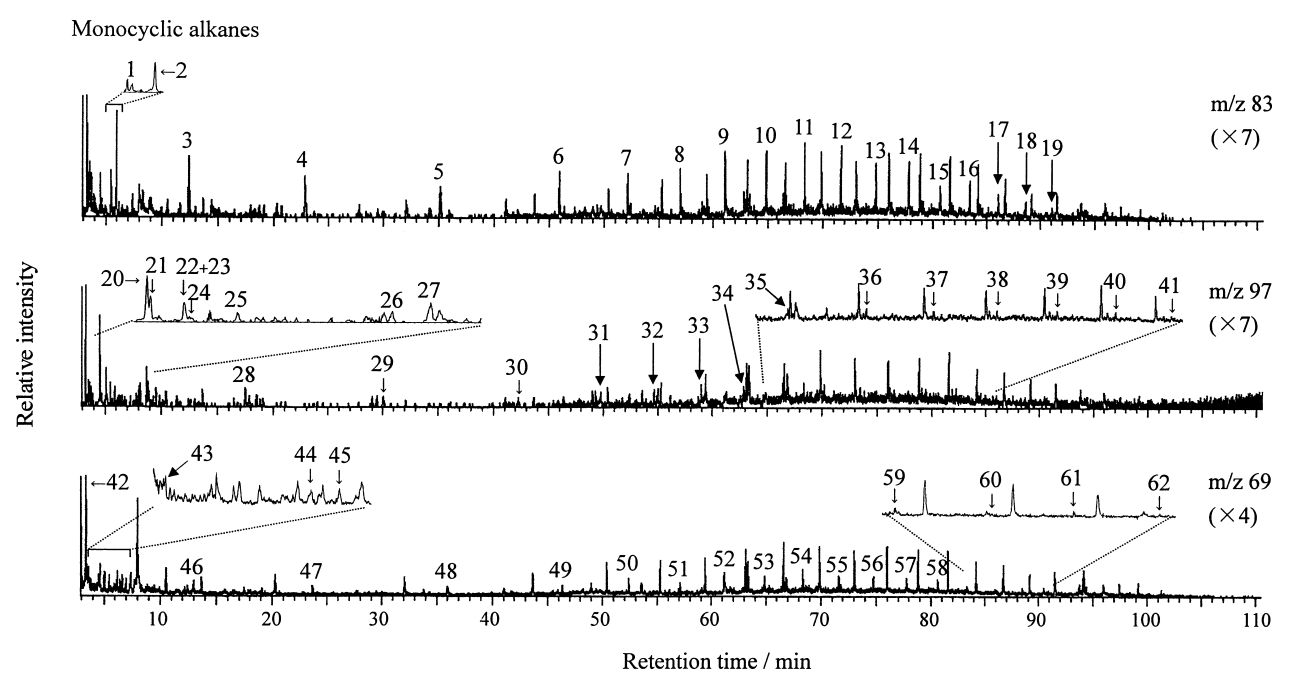

Fig. 1. Mass fragmentograms of $m / z 83$ for n-alkylcyclohexanes and iso-propylcyclohexane, $m / z$, 97 for methyl-nalkylcyclohexanes, and $\mathrm{m} / 269$ for $n$-alkylcyclopentanes, and tri-and tetramethylcyclohexanes in the K/T boundary claystone ( 0.8 to $1.8 \mathrm{~cm}$ ) obtained by GC-MS analysis with a DB-5 capillary column $(30 \mathrm{~m} \times 0.25 \mathrm{~mm}$ i.d., 0.1 $\mu \mathrm{m}$ thick). Peak numbers correspond to those in Table 1. 
Table 1. Cyclic alkanes identified in the K/T sediment samples

\begin{tabular}{|c|c|c|c|}
\hline Peak No. & Compound & Base $\mathrm{m} / \mathrm{z}$ & Identification \\
\hline & Monocyclic alkanes & & \\
\hline 1 & iso-Propylcyclohexane & 83,126 & Std \\
\hline 2 & $n$-Propylcyclohexane & 83,126 & Std \\
\hline 3 & $n$-Butylcyclohexane & 83 & Std \\
\hline 4 & $n$-Pentylcyclohexane & 83 & Std \\
\hline 5 & $n$-Hexylcyclohexane & 83 & Std \\
\hline 6 & $n$-Heptylcyclohexane & 83 & Std \\
\hline 7 & $n$-Octylcyclohexane & 83 & Std \\
\hline 8 & $n$-Nonylcyclohexane & 83 & Std \\
\hline 9 & $n$-Decylcyclohexane & 83 & Std \\
\hline 10 & $n$-Undecylcyclohexane & 83 & Std \\
\hline 11 & $n$-Dodecylcyclohexane & 83 & Std \\
\hline 12 & $n$-Tridecylcyclohexane & 83 & Std \\
\hline 13 & $n$-Tetradecylcyclohexane & 83 & Std \\
\hline 14 & $n$-Pentadecylcyclohexane & 83 & Std \\
\hline 15 & $n$-Hexadecylcyclohexane & 83 & Std \\
\hline 16 & $n$-Heptadecylcyclohexane & 83 & Std \\
\hline 17 & $n$-Octadecylcyclohexane & 83 & Std \\
\hline 18 & $n$-Nonadecylcyclohexane & 83 & Std \\
\hline 19 & $n$-Eicosylcyclohexane & 83 & Std \\
\hline 20 & 3-Methyl-1-ethylcyclohexane (cis) & 97,126 & Std \\
\hline 21 & 4-Methyl-1-ethylcyclohexane (trans) & 97,126 & Std \\
\hline \multirow{2}{*}{$\left.{ }_{23}^{22}\right\}$ and/or } & 2-Methyl-1-ethylcyclohexane (trans) & 97,126 & Std \\
\hline & 3-Methyl-1-ethylcyclohexane (trans) & 97,126 & Std \\
\hline 24 & 4-Methyl-1-ethylcyclohexane (cis) & 97,126 & Std \\
\hline 25 & 2-Methyl-1-ethylcyclohexane (cis) & 97,126 & Std \\
\hline 26 & 4-Methyl-1-isopropylcyclohexane (trans) & 97,140 & Std \\
\hline 27 & Methyl- $n$-propylcyclohexane & 97 & Fowler et al. (1986) \\
\hline 28 & Methyl- $n$-butylcyclohexane & 97 & Fowler et al. (1986) \\
\hline 29 & Methyl- $n$-pentylcyclohexane & 97 & Fowler et al. (1986) \\
\hline 30 & Methyl- $n$-hexylcyclohexane & 97 & Fowler et al. (1986) \\
\hline 31 & Methyl- $n$-heptylcyclohexane & 97 & Fowler et al. (1986) \\
\hline 32 & Methyl- $n$-octylcyclohexane & 97 & Fowler et al. (1986) \\
\hline 33 & Methyl- $n$-nonylcyclohexane & 97 & Fowler et al. (1986) \\
\hline 34 & Methyl- $n$-decylcyclohexane & 97 & Fowler et al. (1986) \\
\hline 35 & Methyl- $n$-undecylcyclohexane & 97 & Fowler et al. (1986) \\
\hline 36 & Methyl- $n$-dodecylcyclohexane & 97 & Fowler et al. (1986) \\
\hline 37 & Methyl- $n$-tridecyclohexane & 97 & Fowler et al. (1986) \\
\hline 38 & Methyl- $n$-tetradecylcyclohexane & 97 & Fowler et al. (1986) \\
\hline 39 & Methyl- $n$-pentadecylcyclohexane & 97 & Fowler et al. (1986) \\
\hline 40 & Methyl- $n$-hexadecylcyclohexane & 97 & Fowler et al. (1986) \\
\hline 41 & Methyl- $n$-heptadecylcyclohexane & 97 & Fowler et al. (1986) \\
\hline
\end{tabular}

al. (1990) and that of Me- $n$-alkylCHs by Fowler et al. (1986). Thus, a total of 62 monocyclic alkanes were identified and they are listed in Table 1 .

n-AlkylCHs from $\mathrm{C}_{9}$ to $\mathrm{C}_{26}$ and other alkylCHs were detected at a concentration level of 0.001$0.1 \mathrm{nmol} \mathrm{g}^{-1}$ (Tables 2 and 3, respectively). All of these compounds were present in most of the sediments. The total concentration of $n$-alkylCHs in each sediment was in a range of $0.30-0.49$ (mean value 0.36 , henceforth m.v. stands for mean value) above, 0.09-0.30 (m.v. 0.16) within, and 0.33-0.51 (m.v. 0.45) nmol g ${ }^{-1}$ below the boundary claystone. The total concentration of other 10 alkylCHs including $6 \mathrm{MeEtCHs}$ in each sediment was in a range of $0.07-0.18$ (m.v. 0.14) above, 
Table 1. (continued)

\begin{tabular}{|c|c|c|c|}
\hline Peak No. & Compound & Base $m / z$ & Identification \\
\hline & Monocyclic alkanes & & \\
\hline 42 & 1,1,3-Trimethylcyclohexane & $69,111,126$ & Std \\
\hline 43 & $1,2,4$-Trimethylcyclohexane & $69,111,126$ & Std \\
\hline 44 & $n$-Butylcyclopentane & 69 & Yamamoto et al. (1990) \\
\hline 45 & $1,1,2,3$-Tetramethylcyclohexane & $69,125,140$ & Lib \\
\hline 46 & $n$-Pentylcyclopentane & 69 & Yamamoto et al. (1990) \\
\hline 47 & $n$-Hexylcyclopentane & 69 & Yamamoto et al. (1990) \\
\hline 48 & $n$-Heptylcyclopentane & 69 & Yamamoto et al. (1990) \\
\hline 49 & $n$-Octylcyclopentane & 69 & Yamamoto et al. (1990) \\
\hline 50 & $n$-Nonylcyclopentane & 69 & Yamamoto et al. (1990) \\
\hline 51 & $n$-Decylcyclopentane & 69 & Yamamoto et al. (1990) \\
\hline 52 & $n$-Undecylcyclopentane & 69 & Yamamoto et al. (1990) \\
\hline 53 & $n$-Dodecylcyclopentane & 69 & Yamamoto et al. (1990) \\
\hline 54 & $n$-Tridecylcyclopentane & 69 & Yamamoto et al. (1990) \\
\hline 55 & $n$-Tetradecylcyclopentane & 69 & Yamamoto et al. (1990) \\
\hline 56 & $n$-Pentadecylcyclopentane & 69 & Yamamoto et al. (1990) \\
\hline 57 & $n$-Hexadecylcyclopentane & 69 & Yamamoto et al. (1990) \\
\hline 58 & $n$-Heptadecylcyclopentane & 69 & Yamamoto et al. (1990) \\
\hline 59 & $n$-Octadecylcyclopentane & 69 & Yamamoto et al. (1990) \\
\hline 60 & $n$-Nonadecylcyclopentane & 69 & Yamamoto et al. (1990) \\
\hline 61 & $n$-Eicosylcyclopentane & 69 & Yamamoto et al. (1990) \\
\hline \multirow[t]{2}{*}{62} & $n$-Heneicosylcyclopentane & 69 & Yamamoto et al. (1990) \\
\hline & Bicyclic alkanes & & \\
\hline 63 & Bicyclo[3.3.1]nonane & 67,124 & Lib \\
\hline 64 & Decalin (trans) & 67,138 & Std \\
\hline 65 & Methyldecalin (isomer A) & 67,152 & $\mathrm{Lib}$ \\
\hline \multirow[t]{3}{*}{66} & Methyldecalin (isomer B) & 67,152 & Lib \\
\hline & Diamondoid hydrocarbons & & \\
\hline & Adamantanes & & \\
\hline 67 & Adamantane & 136 & Std \\
\hline 68 & 1-Methyladamantane & 135 & Wingert (1992); Chen et al. (1996) \\
\hline 69 & 2-Methyladamantane & 135 & Wingert (1992); Chen et al. (1996) \\
\hline 70 & 1,3-Dimethyladamantane & 149 & Wingert (1992); Chen et al. (1996) \\
\hline 71 & 1,4-Dimethyladamantane (trans) & 149 & Wingert (1992); Chen et al. (1996) \\
\hline 72 & 1,4-Dimethyladamantane (cis) & 149 & Wingert (1992); Chen et al. (1996) \\
\hline \multirow[t]{2}{*}{73} & 1,2-Dimethyladamantane & 149 & Wingert (1992); Chen et al. (1996) \\
\hline & Diamantanes & & \\
\hline 74 & Diamantane & 188 & Std \\
\hline 75 & 1-Methyldiamantane & 187 & Wingert (1992); Chen et al. (1996) \\
\hline 76 & 4-Methyldiamantane & 187 & Wingert (1992); Chen et al. (1996) \\
\hline 77 & 2-Methyldiamantane & 187 & Wingert (1992); Chen et al. (1996) \\
\hline
\end{tabular}

Std; standard, Lib; library data (NIST).

$0.01-0.18$ (m.v. 0.07) within, and 0.13-0.56 (m.v. $0.40) \mathrm{nmol} \mathrm{g}^{-1}$ below the boundary claystone. Although the concentrations of Me- $n$-alkylCHs, $n$ alkylCPs, and 1,1,2,3-tetraMeCH were not estimated, they were likely present at the same level of $n$-alkylCHs, judging from their peak areas on the mass fragmentograms.

\section{Bicyclic alkanes}

Figure 2a shows mass fragmentograms of $\mathrm{m} / \mathrm{z}$ 67 (a major ion for bicyclic alkanes), $\mathrm{m} / \mathrm{z} 124$ (a molecular ion for bicyclo[3.3.1]nonane), $\mathrm{m} / \mathrm{z} 138$ (decalin), and $\mathrm{m} / \mathrm{z} 152$ (methyldecalins) for compounds recovered from the sediment $(-10 \mathrm{~cm})$ below the boundary claystone. These four bicy- 


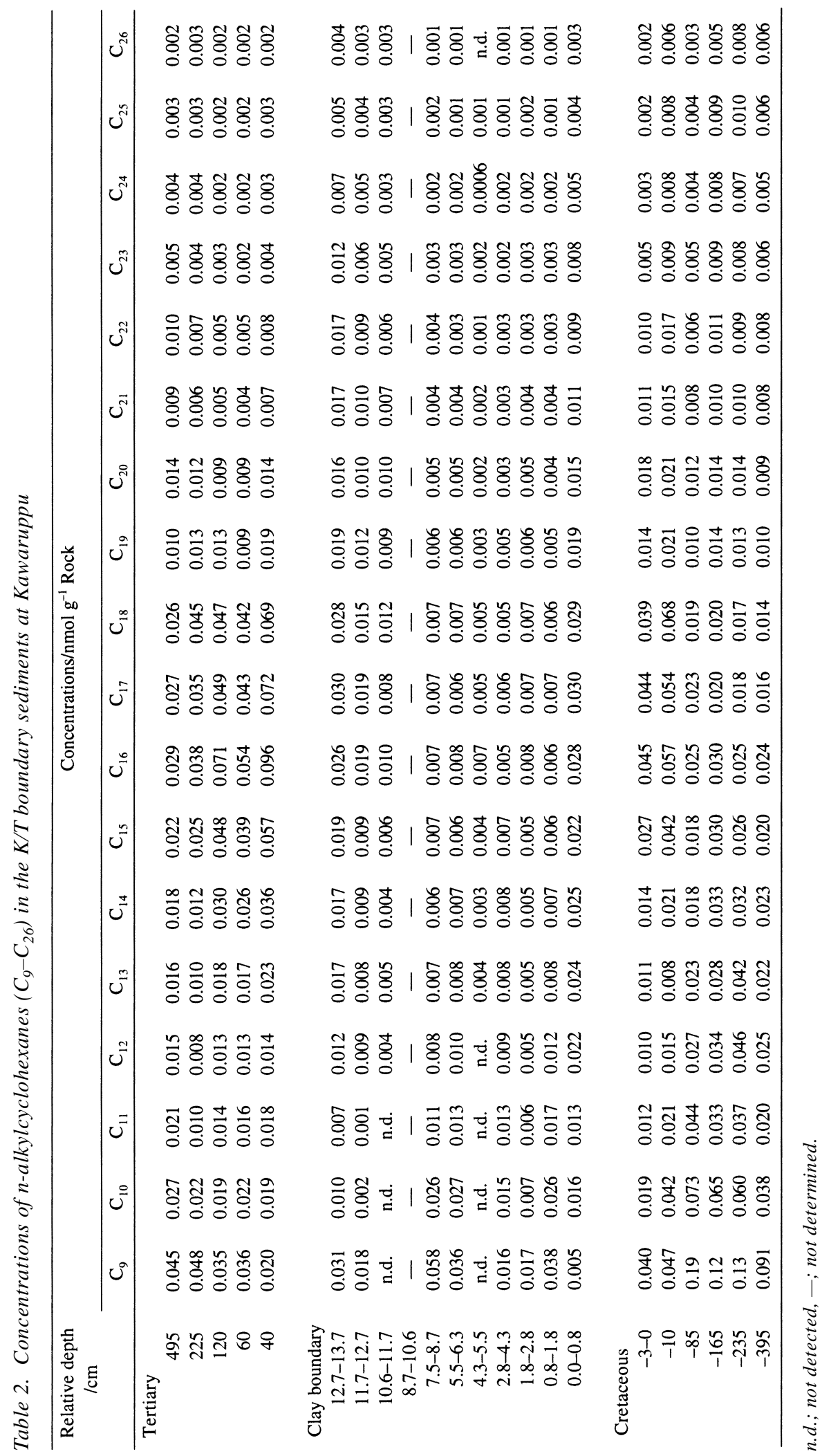




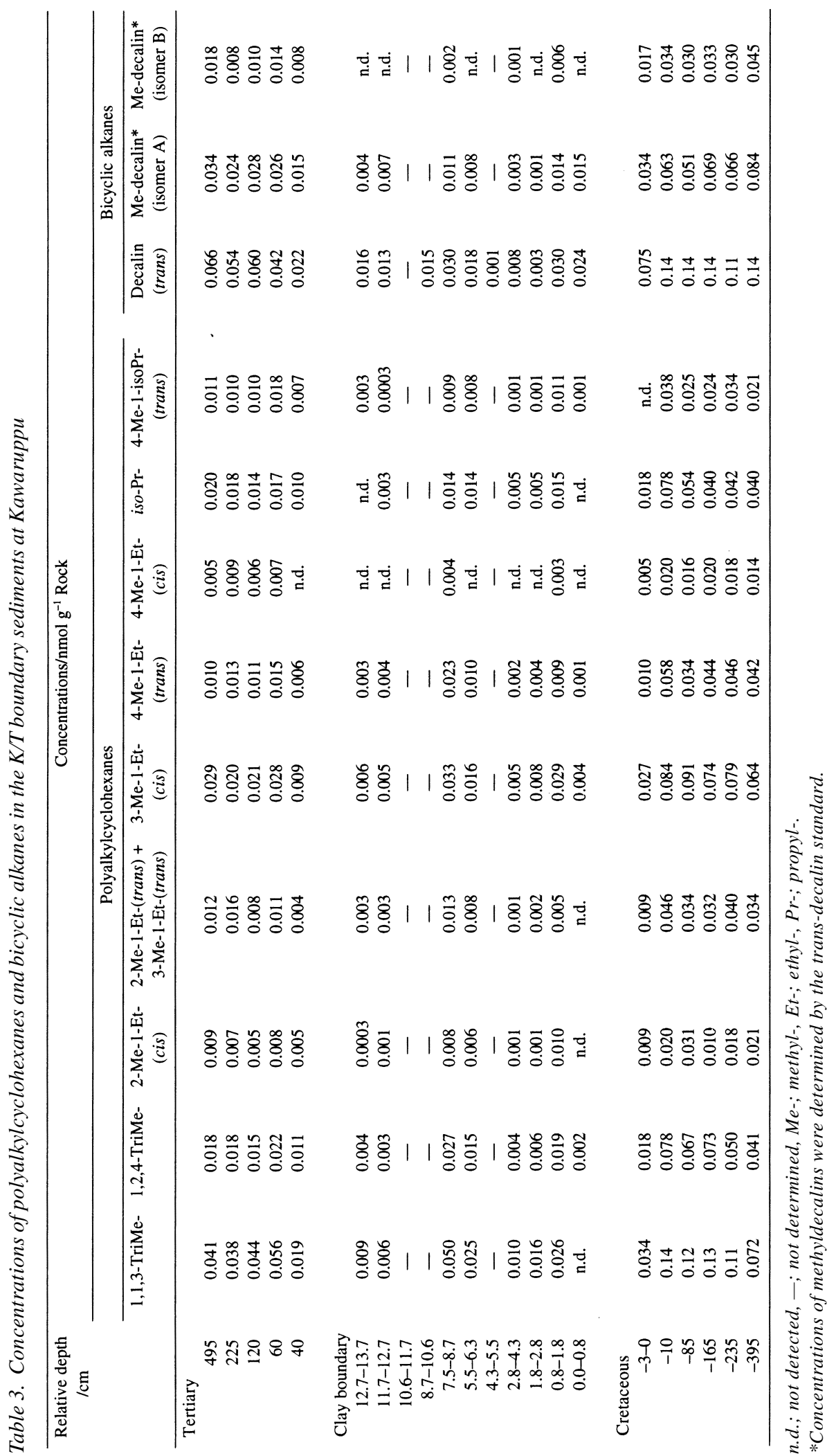


a)

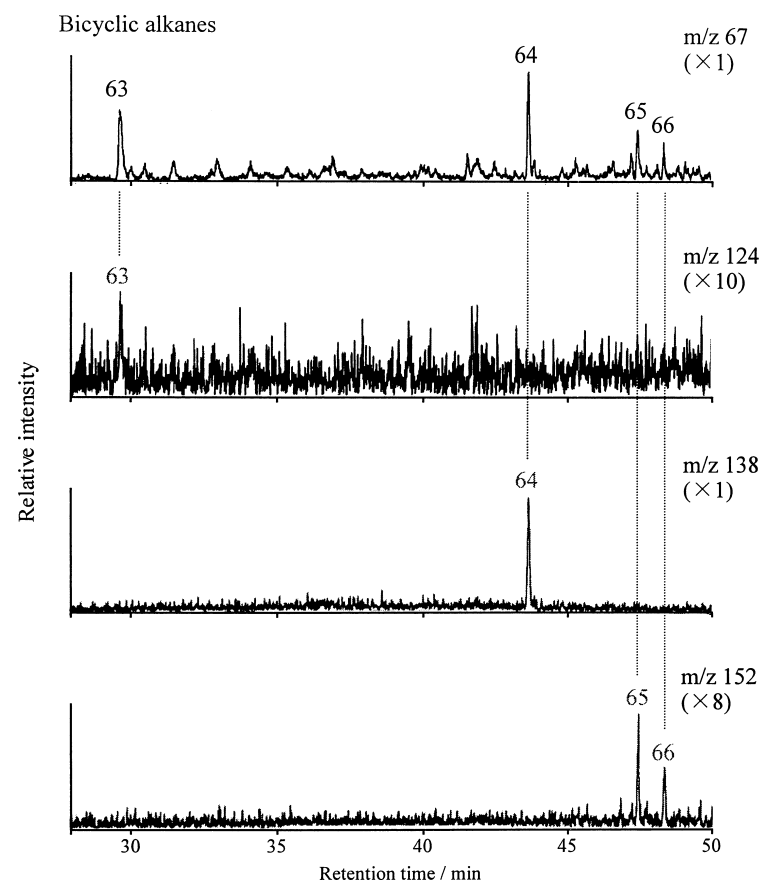

b)

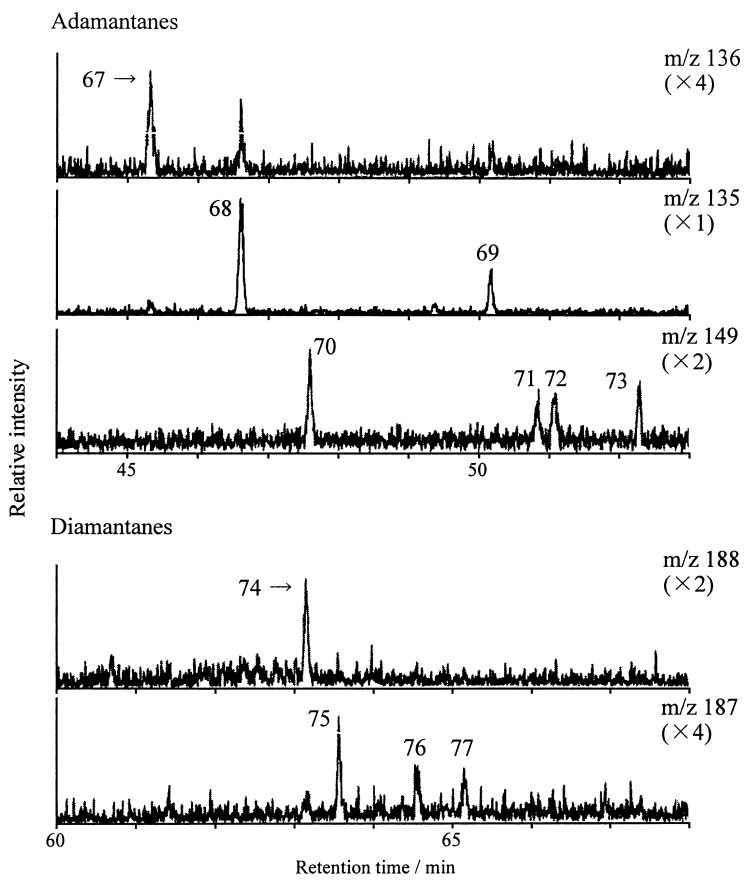

Fig. 2. Mass fragmentograms of a) $\mathrm{m} / \mathrm{z}$ 67, 124, 138, and 152 for bicyclic alkanes and b) $\mathrm{m} / \mathrm{z}, 135$, 136, and 149 for adamantanes and $\mathrm{m} / \mathrm{z} 187$ and 188 for diamantanes in the K/T boundary sediment $(-10 \mathrm{~cm})$ obtained by $G C$ MS analysis with a TC-1 capillary column (60 $\mathrm{m} \times 0.25 \mathrm{~mm}$ i.d., $0.25 \mu \mathrm{m}$ thick). Peak numbers correspond to those in Table 1.

clic alkanes are listed in Table 1. The two isomers of methyldecalins were arbitrarily named as isomer $\mathrm{A}$ for the one at retention time $47.5 \mathrm{~min}$ and isomer B for the other at $48.4 \mathrm{~min}$, because the methyl position on the decalin structure could not be determined.

Decalins were detected at a concentration level of 0.001-0.1 nmol g $\mathrm{g}^{-1}$ (Table 3). The concentration of decalin (trans) in each sediment was in a range of 0.02-0.07 (m.v. 0.05) above, 0.001-0.03 (m.v. 0.02) within, and 0.08-0.14 (m.v. 0.12) $\mathrm{nmol} \mathrm{g}^{-1}$ below the boundary claystone. The total concentration of methyldecalins in each sediment was in a range of 0.02-0.05 (m.v. 0.04) above, 0.001-0.02 (m.v. 0.01) within, and 0.05-0.13 (m.v. $0.09) \mathrm{nmol} \mathrm{g}^{-1}$ below the boundary claystone. Bicyclo[3.3.1]nonane was detected in two sediments $(495 \mathrm{~cm}$ and $225 \mathrm{~cm}$ ) above, two sediments $(0.8-1.8 \mathrm{~cm}$ and $7.5-8.7 \mathrm{~cm})$ within, and most sediments below the claystone. The compound was likely present at the same concentration level of decalins, judging from their peak areas on the mass fragmentograms.

\section{Diamondoid hydrocarbons (adamantanes and diamantanes)}

Figure $2 \mathrm{~b}$ shows mass fragmentograms for compounds recovered from the sediment $(-10 \mathrm{~cm})$ below the boundary claystone. These fragment ions are of adamantanes $(\mathrm{m} / \mathrm{z} 135,136$, and 149) and diamantanes $(\mathrm{m} / \mathrm{z} 187$ and 188). Adamantane and diamantane were identified by their standard compounds (Peaks 67 and 74, respectively, in Fig. 3). Methyl- and dimethyladamantanes and methyldiamantanes were identified using data by Wingert (1992) and Chen et al. (1996). Mass spectra of these compounds showed that molecular ions $\mathrm{M}^{+}$or fragment ions $\left(\mathrm{M}-\mathrm{CH}_{3}\right)^{+}$were the most 

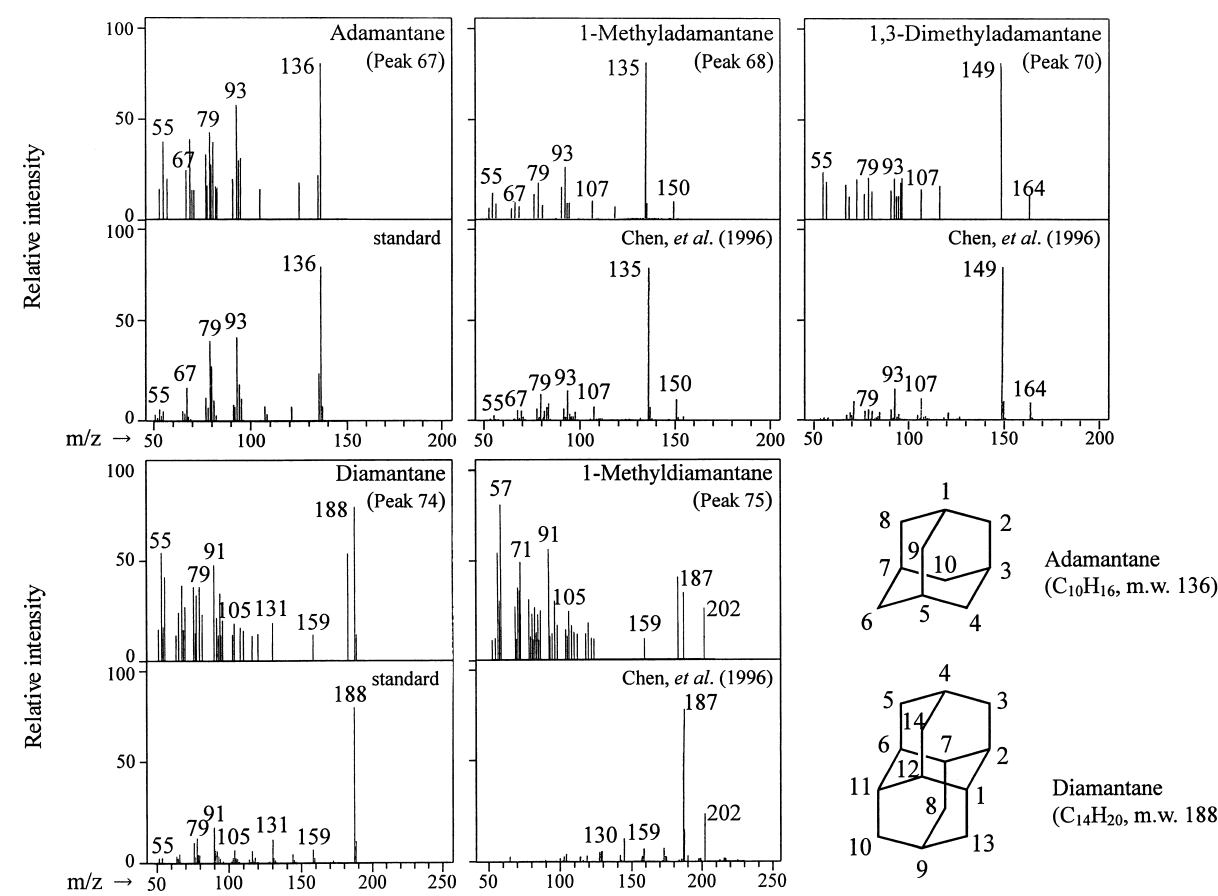

Diamantane

$\left(\mathrm{C}_{14} \mathrm{H}_{20}\right.$, m.w. 188)

Fig. 3. Mass spectra of adamantanes and diamantanes in the K/T boundary sediment $(-10 \mathrm{~cm})$.

abundant (Fig. 3). Thus, 11 diamondoid hydrocarbons were identified and are listed in Table 1. They included adamantane, 2 isomers of methyladamantanes, 4 isomers of dimethyladamantanes, diamantane, and 3 isomers of methyldiamantanes. Some mass spectra contained ions which were considered to be of other compounds as seen in peaks 74 and 75 in Fig. 3. However, the quantification of these diamondoids was made on their mass chromatograms, so that impurities could be excluded.

Adamantanes were detected at a concentration level of $0.001-0.1 \mathrm{nmol} \mathrm{g}^{-1}$ and diamantanes at 0.001-0.01 nmol g-1 (Table 4). These concentration levels were same or one order of magnitude less than those of mono- and bicyclic alkanes. Most of these diamondoid hydrocarbons were scarcely present within the claystone, whereas 1methyladamantane, 1,3-dimethyladamantane, and 4-methyldiamantane were present notably compared with other compounds. The total concentration of 11 diamondoid hydrocarbons in each sediment was in a range of $0.12-0.34$ (m.v. 0.21) above, 0.003-0.06 (m.v. 0.02) within, and 0.090.58 (m.v. 0.38) nmol g ${ }^{-1}$ below the boundary claystone.

Mono- and bicyclic alkanes and diamondoid hydrocarbons detected in the $\mathrm{K} / \mathrm{T}$ boundary sediments were at two orders of magnitude less in concentration than $n$-alkanes $\left(\mathrm{C}_{12}-\mathrm{C}_{36}\right)$ in the same sediments (Mita and Shimoyama, 1999a).

\section{DISCUSSION}

\section{Depth profiles}

Marked decreases in concentration of all cyclic alkanes were observed from the sediment $(-3-0 \mathrm{~cm})$ below the boundary claystone to the bottom sediment $(0-0.8 \mathrm{~cm})$ in the boundary claystone (Fig. 4). Over the K/T boundary, the concentrations of $n$-alkylCHs $\left(\mathrm{C}_{9}-\mathrm{C}_{26}\right)$, Me-nalkylCHs $\left(\mathrm{C}_{9}-\mathrm{C}_{24}\right)$, and $n$-alkylCPs $\left(\mathrm{C}_{9}-\mathrm{C}_{26}\right)$ decreased to around the $25 \%$ levels of those in the sediments below the boundary claystone (Fig. 4a). These decreased concentrations continued over the lower two-third portion $(0-10.6 \mathrm{~cm})$ of the bound- 


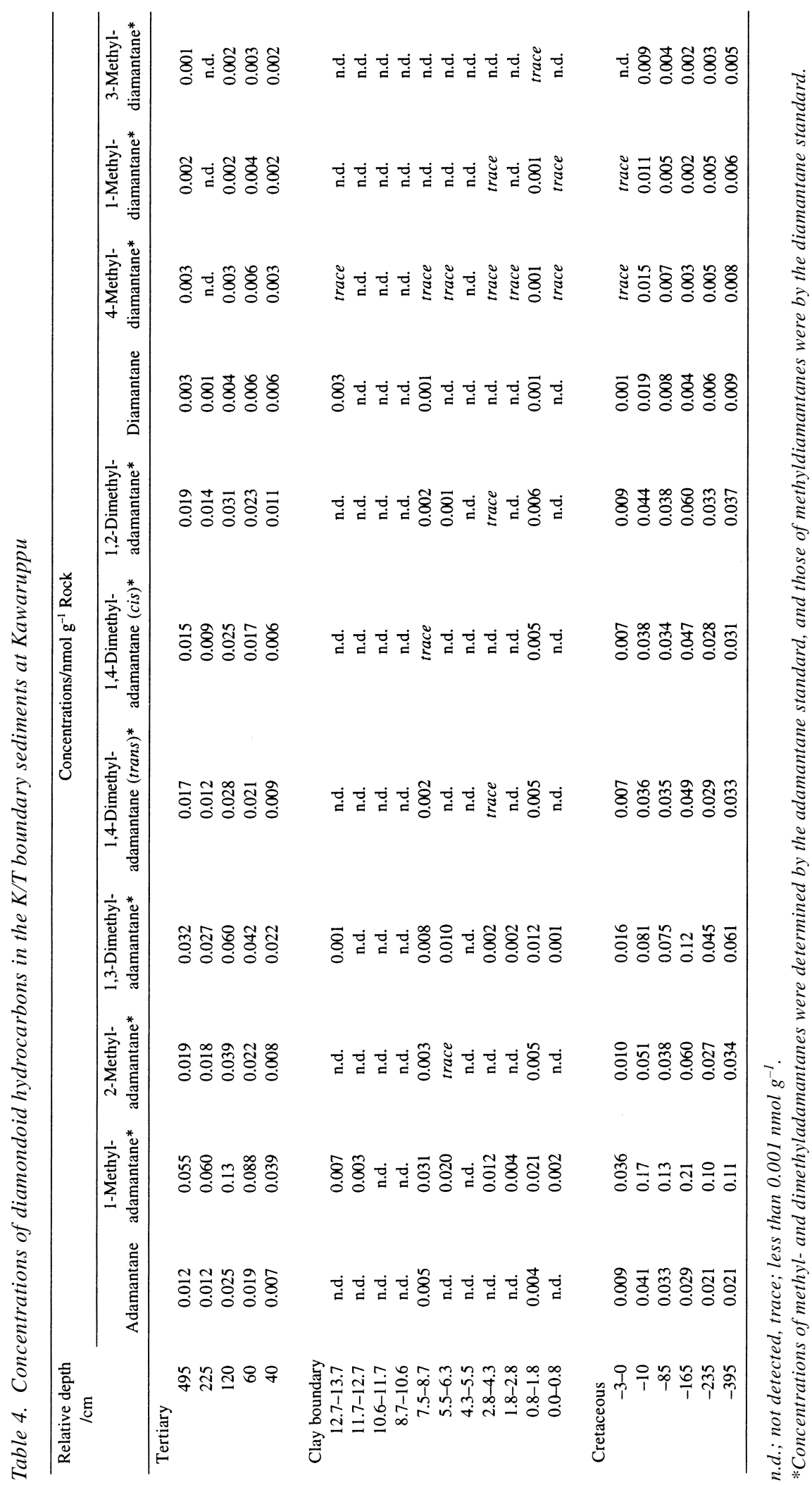




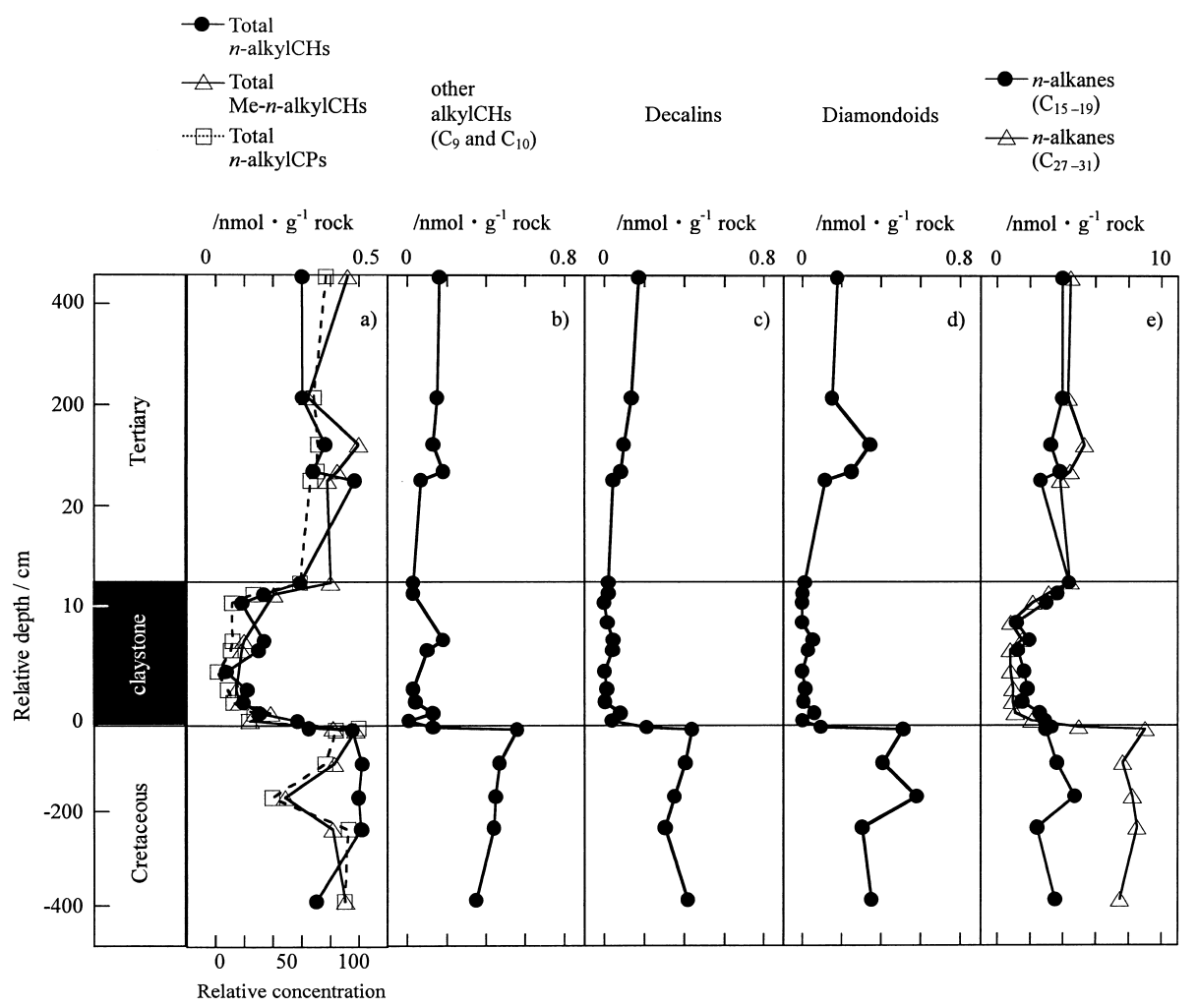

Fig. 4. Depth profiles of a) concentrations of total n-alkylCHs (cyclohexanes, $\left.C_{9-26}\right)$, and relative concentrations of total Me-n-alkylCHs (methyl-n-alkylcyclohexanes, $C_{9-24}$ ) and total n-alkylCPs (cyclopentanes, $\left.C_{9-26}\right)($ maximum concentration set to 100$)$, b) concentrations of total other alkylCHs $\left(C_{9}\right.$ and $\left.\left.C_{10}\right), c\right)$ total decalins, d) total diamondoid hydrocarbons, and e) short $\left(C_{15-19}\right)$ and long chain $\left(C_{27-31}\right)$ n-alkanes (Mita and Shimoyama, 1999a) in the K/T boundary sediments at Kawaruppu.

ary claystone. Then, they began to increase gradually in the upper one third $(10.6-13.7 \mathrm{~cm})$ of the claystone, reaching over the $80 \%$ level at the top of the boundary claystone, and remained rather constant in the sediments above the claystone. This depth profile resembled those of short chain $n$ alkanes $\left(\mathrm{C}_{15}-\mathrm{C}_{19}\right)$ in Fig. 4e (Mita and Shimoyama, 1999a). Concentrations of other alkylCHs, decalins, and diamondoid hydrocarbons decreased to the 10-15\% levels (Figs. 4b, c, and $\mathrm{d}$, respectively). These decreased concentrations roughly remained to the top of the claystone and increased slightly to the $30-45 \%$ levels in the sediments above the claystone. This depth profile resembled those of long chain $n$-alkanes $\left(\mathrm{C}_{27}-\mathrm{C}_{31}\right)$ in Fig. 4e (Mita and Shimoyama, 1999a).
The large concentration decrease of cyclic alkanes at the K/T boundary is probably due to a large decrease in biomass input into the boundary claystone, which related to the massive extinctions of organisms, as observed in the case of $n$-alkanes, pristane, and phytane (Mita and Shimoyama, 1999a). Differences in decrease among cyclic alkanes in the boundary claystone and in increase in the sediments above the claystone might have been caused by their difference in biological source. According to these depth profiles, living organisms which had been sources of $n$ alkylcycloalkanes had recovered to the abundance level of the Cretaceous at the sediment $(40 \mathrm{~cm})$ depositional time ( $c a .50000$ years after the boundary). Whereas, those which had been sources of 
other alkylCHs, decalins, and diamondoids had not recovered even to a half abundance level at the sediment $(495 \mathrm{~cm})$ time $(\mathrm{ca} .550000$ years after the boundary). The 50000 and 550000 years were estimated using data by Kajiwara and Kaiho (1992).

Both $n$-alkylCHs and Me- $n$-alkylCHs have been detected in various geological samples including mature crude oil (Rubinstein and Strausz, 1979), Ordovician sediments (Fowler and Douglas, 1984; Fowler et al., 1986; Hoffmann et al., 1987) and the fossil alga (G. priska) (Hoffmann et al., 1987), Eocene oil shales (Ingram et al., 1983), and ODP Hole sediments of Late Miocene (Yamamoto et al., 1990). It has been suggested that $n$-alkylCHs and Me- $n$-alkylCHs were formed by cyclization of $n$-fatty acids and they were likely derived from marine organisms such as algae (Rubinstein and Strausz, 1979; Fowler et al., 1986; Hoffmann et al., 1987). Rubinstein and Strausz (1979) demonstrated experimentally the formation of $n$-alkylCHs and Me- $n$-alkylCHs mainly in a range of $\mathrm{C}_{15}$ to $\mathrm{C}_{18}$ by heating stearic (saturated) and oleic (unsaturated) acids $\left(\mathrm{C}_{18}\right)$ in the presence of bentonite. As to $n$-alkylCPs, it was suggested that they were formed by cyclization of unsaturated fatty acids during diagenesis (Philp, 1980). Therefore, it is very likely that these $n$ alkylCHs and Me-n-alkylCHs in the $\mathrm{K} / \mathrm{T}$ sediments at Kawaruppu were derived from biological fatty acids, as it was the case for $n$-alkanes. Furthermore, the similarity in their depth profiles to that of the short chain $n$-alkanes $\left(\mathrm{C}_{15}-\mathrm{C}_{19}\right)$ suggested that they were derived from fatty acids of marine organisms. In addition, it has been suggested that $n$-alkylcyclohexanes were produced by decarboxylation of $\omega$-cyclohexyl fatty acids in thermoacidophilic bacterial products (De Rosa et al., 1972; Oshima and Ariga, 1975; Suzuki et al., 1981). However, contribution from thermoacidophilic bacteria is probably insignificant because of the K/T sedimentary environment at Kawaruppu.

Anders and Robinson (1971) proposed that polyalkylCHs and bicyclic alkanes were derived by degradation of some terpenoids. It was also reported that polyalkyl- $\mathrm{CHs}\left(\mathrm{C}_{7}-\mathrm{C}_{9}\right)$ and $\mathrm{CPs}\left(\mathrm{C}_{6}\right.$ and $\mathrm{C}_{7}$ ) were produced by heating $5 \alpha$-cholestane in the presence of clay, although in small yields (Kissin, 1990). Diamondoid hydrocarbons are known to be formed by heating with a strong Lewis acid catalyst from some polycyclic alkanes (Petrov et al., 1974), which can be derived from terpenoids in sediments. PolyalkylCHs, bicyclic alkanes, and diamondoid hydrocarbons are likely derived from these terrestrial terpenoids. The similar depth profiles of these compounds to those of long chain $n$-alkanes $\left(\mathrm{C}_{27}-\mathrm{C}_{31}\right)$ support above interpretation. Therefore, precursors and their biological sources of these cycloalkanes are possibly different from those of $n$-alkylcycloalkanes, which might explain the difference in their depth profiles from those of $n$-alkylcycloalkanes.

\section{Molecular distribution of n-alkylcycloalkanes}

The molecular distributions of $n$-alkylCHs $\left(\mathrm{C}_{15}-\mathrm{C}_{26}\right)$, Me- $n$-alkylCHs $\left(\mathrm{C}_{15}-\mathrm{C}_{24}\right)$, and $n$ alkylCPs $\left(\mathrm{C}_{15}-\mathrm{C}_{26}\right)$ in each sediment were shown in Fig. 5, together with those of $n$-alkanes $\left(\mathrm{C}_{15^{-}}\right.$ $\mathrm{C}_{36}$ ) (Mita and Shimoyama, 1999a). The abundances of $n$-alkylCHs in most sediments within the boundary claystone were small and roughly similar to each other. On the other hand, those in the sediments above and below the boundary claystone showed predominances in a range of $\mathrm{C}_{15}-\mathrm{C}_{18}$. The molecular distributions of Me- $n$ alkylCHs were roughly similar to those of $n$ alkylCHs in most sediments. $n$-AlkylCPs also showed a similar distribution feature as those of the former two homologues, except that even carbon number predominances in a range of $\mathrm{C}_{16}-\mathrm{C}_{22}$, as opposed to rather smooth distributions of the two former homologues in the carbon range.

The molecular distributions of the three series did not resemble those of $n$-alkanes which showed clearly high abundances in a range of $\mathrm{C}_{25}-\mathrm{C}_{31}$ (Fig. $5)$. The difference in predominance of $n$ alkylcycloalkanes $\left(\mathrm{C}_{15}-\mathrm{C}_{18}\right)$ and $n$-alkanes $\left(\mathrm{C}_{25^{-}}\right.$ $\mathrm{C}_{31}$ ) might be related to the different sources and formation processes from biological fatty acids which are rich in $\mathrm{C}_{16}-\mathrm{C}_{18}$ and $\mathrm{C}_{28}-\mathrm{C}_{30}$. The cyclization might proceed rather efficiently with 

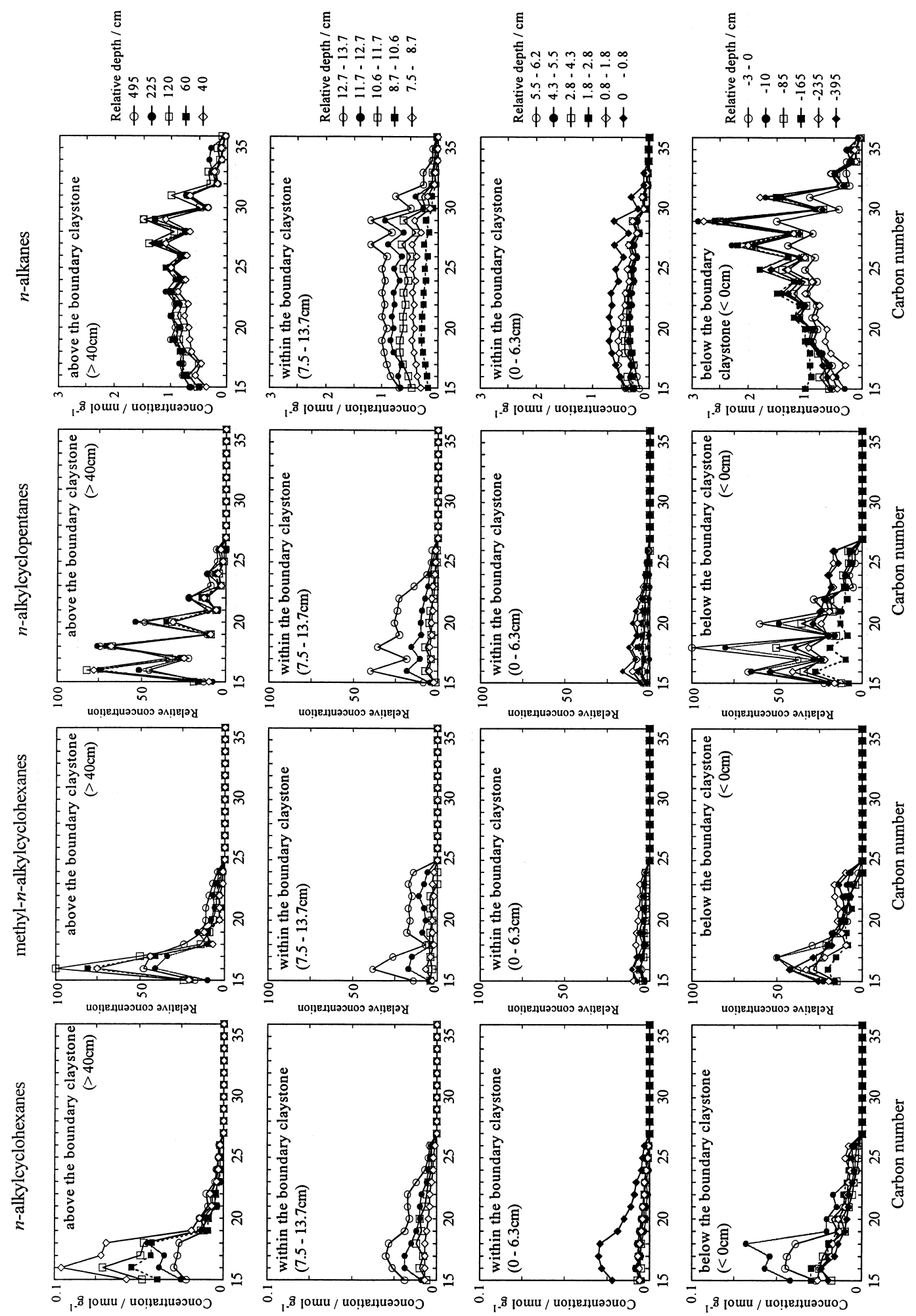

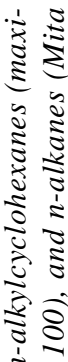

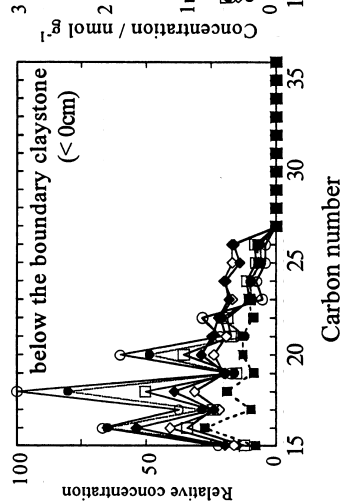

$\stackrel{1}{i} 2$

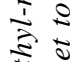

ฐ

จิ

\%

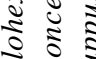

¿

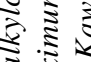

i.

ऽ

के

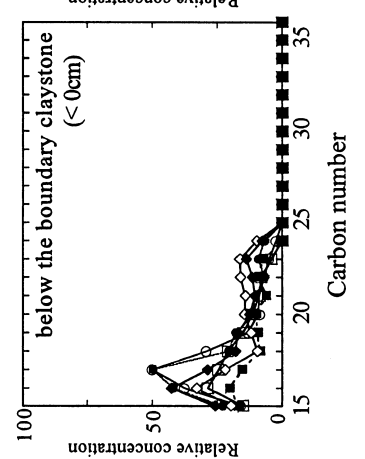

)

5

0 .

ป

$5 \approx$

I

ڤิ)

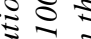

요요

కั

เ

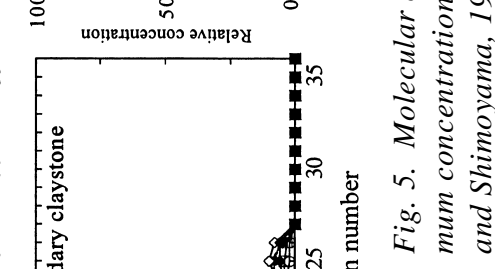


fatty acids of carbon chain length of $\mathrm{C}_{16}-\mathrm{C}_{18}$ generally derived from marine organisms than the longer one, which produced the $n$ alkylcycloalkane predominances in the carbon range. Whereas, decarboxylation probably takes place nearly evenly over fatty acids with $\mathrm{C}_{16}-\mathrm{C}_{30}$, which caused the $n$-alkane predominance in the range of $\mathrm{C}_{25}-\mathrm{C}_{31}$ due to the abundance of source fatty acids with $\mathrm{C}_{28}-\mathrm{C}_{30}$ from land plants.

The relatively smooth molecular distributions of the four homologues (including $n$-alkanes) within the boundary claystone seem to indicate that they were older than those above and below the claystone. However, the depth profiles of these series clearly reflected the biomass extinctions. Therefore, the smooth molecular distributions might have been related to the depositional environment of the claystone besides the small biomass input into it. If so, the relatively high concentrations or compositions from $\mathrm{C}_{15}$ to $\mathrm{C}_{18}$ of three $n$ alkylcycloalkane homologues in the upper two sediments $(11.7-13.7 \mathrm{~cm})$ within the claystone were likely related to the recovery processes of the environment as well as their precursors input.

Carbon preference indices (CPIs) of $n$ alkylCHs $\left(\mathrm{C}_{15}-\mathrm{C}_{26}\right)$, Me- $n$-alkylCHs $\left(\mathrm{C}_{15}-\mathrm{C}_{26}\right)$, and $n$-alkylCPs $\left(\mathrm{C}_{15}-\mathrm{C}_{26}\right)$ were calculated in each sediment by the equation

$$
\mathrm{CPI}=\sum_{i=8}^{13} C_{2 i-1} / \sum_{i=8}^{13} C_{2 i}
$$

where $i$ is number of carbon atoms in the molecules.

CPIs of $n$-alkylCHs in the sediments above, within, and below the claystone were in a range of 0.8-0.9 (m.v. 0.9), 0.9-1.3 (m.v. 1.1), and 0.81.1 (m.v. 1.1), respectively. Those of Me- $n$ alkylCHs were 0.7-1.0 (m.v. 0.9), 1.0-1.2 (m.v. 1.1), and 1.0-1.3 (m.v. 1.1), respectively. These values are more or less close to 1 , indicating that the two homologues once formed from fatty acids received the diagenetic alteration which produced smooth molecular distributions. On the other hand, CPIs of $n$-alkylCPs were 0.3-0.4 (m.v. 0.3), 0.60.9 (m.v. 0.8), and 0.4-0.7 (m.v. 0.6), respectively.
These values clearly showed an even carbon number predominance as seen in Fig. 5. If $n$ alkylCPs were formed from unsaturated fatty acids (Philp, 1980), the values should have been close to 1 similarly to those of $n$-alkylCHs and Me- $n$-alkylCHs. Presently it can only be said that the precursors and formation paths were different for $n$-alkylCPs from $n$-alkylCHs and $\mathrm{Me}-n$ alkylCHs. This may relate why $\mathrm{C}_{20}$ molecule in addition to $\mathrm{C}_{16}$ and $\mathrm{C}_{18}$ ones were predominant among $n$-alkylCPs, while the $\mathrm{C}_{20}$ predominance was not observed for the other two homologues.

Compositions of cyclic alkanes (trimethyl-and methylethylcyclohexanes, decalins, adamantanes, and diamantanes)

Depth profiles of the compound compositions among triMeCHs, MeEtCHs, decalins, methyladamantanes, and methyldiamantanes are shown in Figs. 6a, b, c, and d, respectively. These compositions were roughly constant over the K/T sediments. This indicated that diagenetic effect to these compounds had been nearly the same in the sediments above, within and below the boundary claystone. Similar results were observed by the ratios of $\beta$ - to $\alpha$-alkylated PAHs (Fig. 6e, Mita and Shimoyama, $1999 \mathrm{~b}), \quad \beta$ - to $\alpha$ methyldibenzothiophenes (Fig. 6e, Katsumata and Shimoyama, 2000), and of alkylmaleimides (Fig. 6f, Shimoyama et al., 2001). This may be understandable from the age difference of about one million year from the bottom to the top sediment of the $\mathrm{K} / \mathrm{T}$ sediment we examined whose age as a whole is $c a$. 65 million years. Therefore, the small concentrations of these cyclic alkanes within the boundary claystone were not caused by the selective degradation by clays but by the small biomass input into the claystone. Additionally, the near constant compositions suggest that their precursors were nearly constant in composition over the $\mathrm{K} / \mathrm{T}$ sediments, but not in abundance due to the massive extinctions.

Decalin (non-substituted) was more abundant than methyldecalins over the sedimentary sequence. This result can be explained by their structural stabilities; i.e., decalin is structurally more 


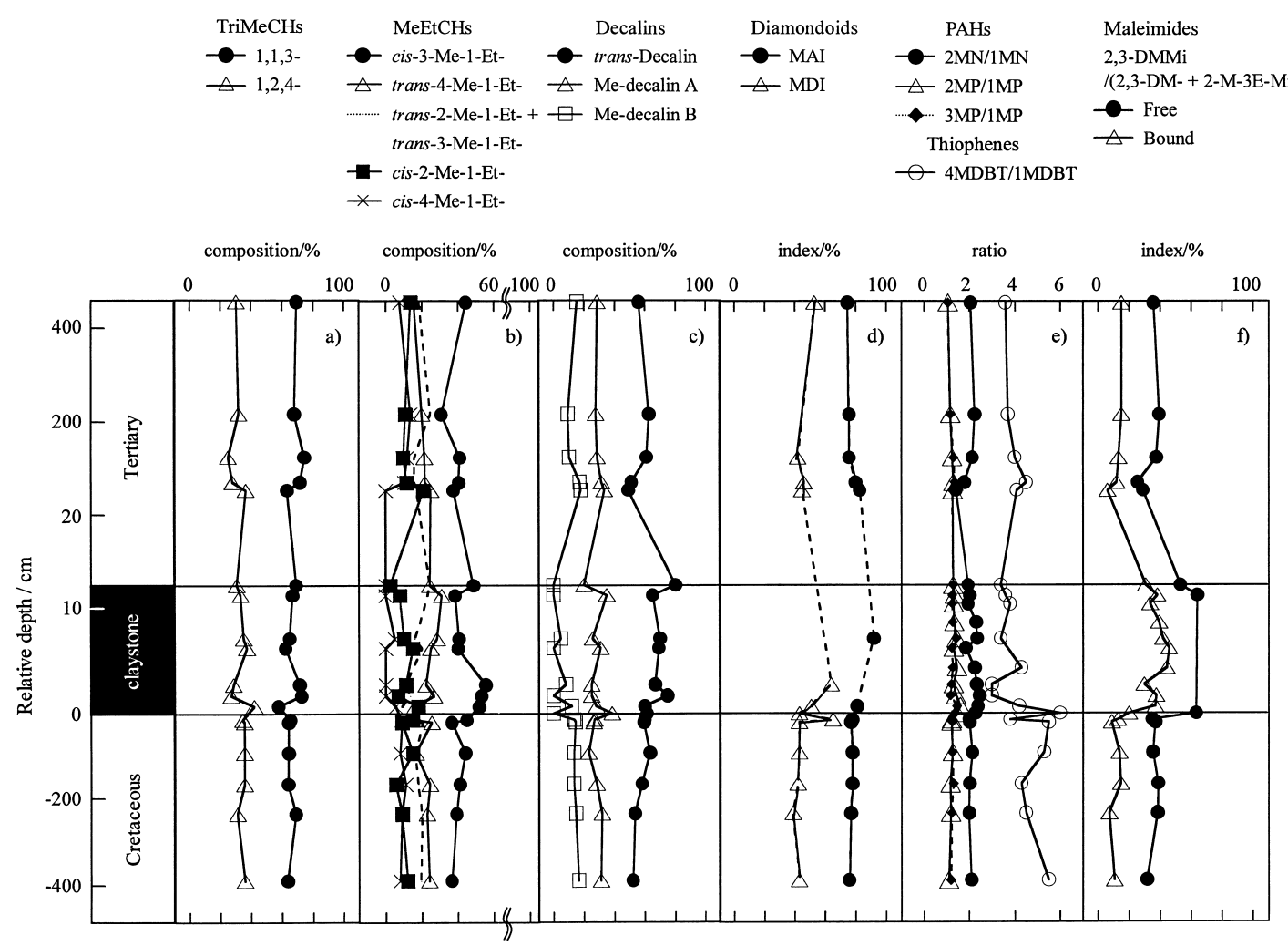

Fig. 6. Depth profiles of a) relative compositions (\%) of triMeCHs (trimethylcyclohexanes), b) MeEtCHs (methylethylcyclohexanes), and c) decalins, d) MAIs (methyladamantane index; 1-MA/(1-MA + 2-MA)) and MDIs (methyldiamantane index; 4-MD/(4-MD + 1-MD + 3-MD)) (the two indices were from Chen et al., 1996), e) ratios of $\beta$ - to $\alpha$-MN (methylnaphthalene), MP (methylphenanthlene) (Mita and Shimoyama, 1999b), and MDBT (methyldibenzothiophene) (Katsumata and Shimoyama, 2000), and f) 2,3-DMMi (2,3-dimethylmaleimide)/(2,3$D M M i+2-M-3 E-M i(2-m e t h y l-3-e t h y l m a l e i m i d e))(S h i m o y a m a ~ e t ~ a l ., 2001)$ in the K/T boundary sediments at Kawaruppu.

stable than methyldecalins. Among diamondoid hydrocarbons, 1-methyladamantane, 1,3dimethyladamantane, and 4-methyldiamantane were predominant (Table 4). The three diamondoids are bridgehead-substituted and most stable among adamantanes and diamantanes. Therefore, the predominances also related to the stabilities of diamondoid structures. Chen et al. (1996) have introduced maturity parameters using the stabilities of methyladamantanes and methyldiamantanes. However, our results were not in accordance with their maturity evaluation indices. Likewise, Schulz et al. (2001) reported that the indices were not applicable to their samples of marine siliciclastic shales, marine carbonates, and coals. Further studies of diamondoid hydrocarbons are necessary for the evaluation of their sources and maturity.

\section{CONCLUSiOnS}

The K/T boundary sediments at Kawaruppu were analyzed for mono- and bicyclic alkanes, and diamondoid hydrocarbons. As a result, 62 monoand 4 bicyclic alkanes, and 11 diamondoid hydrocarbons were detected at a concentration level of sub-nmol or pmol $\mathrm{g}^{-1}$. Concentrations of all cyclic alkanes were found to relate to the large biomass extinction at the Cretaceous end. Among the cyclic alkanes, $n$-alkylcycloalkanes showed a 
rather quick recovery of their biological sources. Other alkyl cyclohexanes, decalins, and diamondoid hydrocarbons showed no complete recovery to the abundance levels of the Cretaceous. Such differences in recovery might have been caused by their differences in biological sources. CPIs of $n$-alkylcyclohexanes and methyl$n$-alkylcyclohexanes indicated that two homologues probably formed from the same biological source. CPIs of $n$-alkylcyclopentanes suggested that their precursors and formation paths were different from those of the above two homologues. Compositions of compounds among trimethylcyclohexanes, methylethylcyclohexanes, decalins, methyladamantanes, and methyldiamantanes were constant over sedimentary sequence, indicating that diagenetic effect to these compounds was probably same over the sediments.

Acknowledgments-We are grateful to Profs. N. Suzuki (Hokkaido University) and S. Yamamoto (Sohka University) for their critical comments on the earlier version of this paper. This work was supported by the Grant-in-Aid for Scientific Research (B) No. 11440166 from the Ministry of Education, Science, Sports and Culture, Japan and the Research Grant for Fellowship No. 00007064 to H. Y. from Japanese Society for the Promotion of Science.

\section{REFERENCES}

Alberdi, M., Moldowan, J. M., Peters, K. E. and Dahl, J. E. (2001) Stereoselective biodegradation of tricyclic terpanes in heavy oils from the Bolivar Coastal Fields, Venezuela. Org. Geochem. 32, 181191.

Anders, D. E. and Robinson, W. E. (1971) Cycloalkane constituents of the bitumen from Green River Shale. Geochim. Cosmochim. Acta 35, 661-678.

Berthod, A., Wang, X., Gahm, K. H. and Armstrong, D. W. (1998) Quantitative and stereoisomeric determination of light biomarkers in crude oil and coal samples. Geochim. Cosmochim. Acta 62, 1619-1630.

Chen, J., Fu, J., Sheng, G., Liu, D. and Zhang, J. (1996) Diamondoid hydrocarbon ratios: novel maturity indices for highly mature crude oils. Org. Geochem. 25, 179-190.

Dahl, J., Moldowan, M., Peters, K., Claypool, G., Rooney, M., Michael, G., Mellos, M. and Kohnen,
M. (1999) Diamondoid hydrocarbons as indicators of natural cracking. Nature 399, 54-56.

De Rosa, M., Gambacorta, A. and Minale, L. (1972) The formation of $\omega$-cyclohexyl-fatty acids from shikimate in an acidophilic thermophilic bacillus. Biochem. J. 128, 751-754.

Farrimond, P., Taylor, A. and Telnaes, N. (1998) Biomarker maturity parameters: the role of generation and thermal degradation. Org. Geochem. 29, 1181-1197.

Fowler, M. G. and Douglas, A. G. (1984) Distribution and structure of hydrocarbons in four organic-rich Ordovician rocks. Org. Geochem. 6, 105-114.

Fowler, M. G., Abolins, P. and Douglas, A. G. (1986) Monocyclic alkanes in Ordovician organic matter. Org. Geochem. 10, 815-823.

Grice, K., Alexander, R. and Kagi, R. (2000) Diamondoid hydrocarbons as indicators of biodegradation in Australian crude oils. Org. Geochem. 31, 67-73.

Hoffman, C. F., Foster, C. B., Powell, T. G. and Summons, R. E. (1987) Hydrocarbon biomarkers from Ordovician sediments and the fossil alga Gloeocapsomorpha priska Zalessky 1917. Geochim. Cosmochim. Acta 51, 2681-2697.

Inaba, T., Suzuki, N., Hirai, A., Sekiguchi, K. and Watanabe, T. (2001) Source rock lithology prediction based on oil diacholestane abundance in the siliceous-clastic Akita sedimentary basin, Japan. Org. Geochem. 32, 877-890.

Ingram, L. L., Ellis, J., Crisp, P. T. and Cook, A. C. (1983) Comparative study of oil shales and shale oils from the Mahogany Zone, Green River Formation (U.S.A.) and Kerosene Creek Seam, Rundle Formation (Australia). Chem. Geol. 38, 185-212.

Jinggui, L., Philp, P. and Mingzhong, C. (2000) Methyl diamantane index (MDI) as a maturity parameter for Lower Palaeozoic carbonate rocks at high maturity and overmaturity. Org. Geochem. 31, 267272.

Kaiho, K. (1992) A low extinction rate of intermediate-water benthic foraminifera at Cretaceous/Tertiary boundary. Mar. Micropaleontol. 18, 229-259.

Kaiho, K. and Saito, T. (1986) Terminal Cretaceous sedimentary sequence recognized in the northernmost Japan based on planktonic foraminifera evidence. Proc. Jpn. Acad. 62(B), 145-148.

Kajiwara, Y. and Kaiho, K. (1992) Oceanic anoxia at the Cretaceous/Tertiary boundary supported by the sulfur isotope record. Paleogeogr. Paleoclim. Paleoecol. 99, 151-162.

Katsumata, H. and Shimoyama, A. (2000) Thiophenes in the Cretaceous/Tertiary boundary sediments at Kawaruppu, Hokkaido, Japan. Geochem. J. 35, 6776. 
Kissin, Y. V. (1990) Catagenesis of light cycloalkanes in petroleum. Org. Geochem. 15, 575-594.

Mita, H. and Shimoyama, A. (1999a) Characterization of $n$-alkanes, pristane and phytane in the Cretaceous/ Tertiary boundary in Kawaruppu, Hokkaido, Japan. Geochem. J. 33, 285-294.

Mita, H. and Shimoyama, A. (1999b) Distribution of polycyclic aromatic hydrocarbons in the K/T boundary sediments at Kawaruppu, Hokkaido, Japan. Geochem. J. 33, 305-315.

Mita, H., Shimoyama, A. and Kajiwara, Y. (1996) Search for extraterrestrial amino acids in sediments at the Cretaceous/Tertiary boundary in Kawaruppu, Hokkaido, Japan. Geochem. J. 30, 89-98.

Mita, H., Fukunaga, N. and Shimoyama, A. (1998) Characterization of dicarboxylic acids in the Cretaceous/Tertiary boundary sediments at Kawaruppu, Hokkaido, Japan and comparison with those of carbonaceous chondrites. Geochim. Cosmochim. Acta 62, 3695-3702.

Oshima, M. and Ariga, T. (1975) Cyclohexyl fatty acids in acidophilic thermophilic bacteria. J. Biol. Chem. 250, 6963-6968.

Peters, K. E. and Moldowan, J. M. (1993) The Biomarker Guide, Interpreting Molecular Fossils in Petroleum and Ancient Sediments. Prentice-Hall, Englewood Cliffs, New Jersey, 363 pp.

Petrov, A., Arefjev, O. A. and Yakubson, Z. V. (1974) Hydrocarbons of adamantane series as indices of petroleum catagenesis process. Advances in Organic Geochemistry 1973 (Tissot, B. and Bienner, F., eds.), 517-522, Technip, Paris.

Philp, R. P. (1980) Comparative organic geochemical studies of recent algal mats and sediments of algal origin. Biogeochemistry of Ancient and Modern En- vironments, 173-187, Australian Academy of Science, Canberra, A.C.T.

Rubinstein, I. and Strausz, O. P. (1979) Geochemistry of the thiourea adduct fraction from an Alberta petroleum. Geochim. Cosmochim. Acta 43, 1387-1392.

Saito, T., Yamanoi, T. and Kaiho, K. (1986) End-Cretaceous devastation of terrestrial flora in the boreal Far East. Nature 323, 253-255.

Schulz, L. K., Wilhelms, A., Rein, E. and Steen, A. S. (2001) Application of diamondoids to distinguish source rock facies. Org. Geochem. 32, 365-375.

Shimoyama, A., Kozono, M., Mita, H. and Nomoto, S. (2001) Maleimides in the Cretaceous/Tertiary boundary sediments at Kawaruppu, Hokkaido, Japan. Geochem. J. 35, 365-375.

Suzuki, K., Saito, K., Kawaguchi, A., Okuda, S. and Komagata, K. (1981) Occurrence of $\omega$-cyclohexyl fatty acids in Curtobacterium pusillum strains. $J$. Gen. Appl. Microbiol. 27, 261-266.

Tazaki, K., Aratani, M., Yanokura, M., Kaiho, K. and Noda, S. (1992) Singularity of clay minerals and iridium concentration at Cretaceous-Tertiary boundary. Nendo-kagaku (Clay Science) 32, 86-96 (in Japanese with English abstract).

Wingert, W. S. (1992) G.C.-M.S. analysis of diamondoid hydrocarbons in Smackover petroleums. Fuel 71, 37-43.

Yabuta, H., Mita, H. and Shimoyama, A. (2002) Detection of mono- and bicyclic alkanes and their characteristics in Neogene sediments of the Shinjo basin, Japan. Geochem. J. 36, 31-49.

Yamamoto, S., Ishiwatari, R., Machihara, T. and Morinaga, S. (1990) Characterization of hydrocarbons from sediments of the Panama Basin (ODP Hole 677A and 678B). Res. Org. Geochem. 7, 41-44. 